Instruments and Methods

\title{
Assessing benthic oxygen fluxes in oligotrophic deep sea sediments (HAUSGARTEN observatory)
}

\author{
Daphne Donis ${ }^{\mathrm{a}, \mathrm{b}, *}$, Daniel F. McGinnis ${ }^{\mathrm{b}}$, Moritz Holtappels ${ }^{\mathrm{c}, \mathrm{d}}$, Janine Felden ${ }^{\mathrm{c}, \mathrm{d}}$, \\ Frank Wenzhoefer ${ }^{\mathrm{a}, \mathrm{c}}$ \\ ${ }^{a}$ HGF-MPG Group for Deep Sea Ecology and Technology, Alfred Wegener Institute for Marine and Polar Research, Bremerhaven, Germany \\ ${ }^{\mathrm{b}}$ Institute F.-A. Forel, Earth and Environmental Sciences, Faculty of Sciences, University of Geneva, Geneva, Switzerland \\ ${ }^{c}$ Max Plank Institute for Marine Microbiology, Bremen, Germany \\ ${ }^{\mathrm{d}}$ MARUM Center for Marine Environmental Sciences, University Bremen, Germany
}

\section{A R T I C L E I N F O}

\section{Article history:}

Received 17 April 2015

Received in revised form

11 November 2015

Accepted 16 November 2015

\section{Keywords:}

Benthic oxygen uptake

Aquatic eddy covariance

In situ oxygen microelectrodes

Benthic chambers

Deep-sea sediments

HAUSGARTEN observatory

\begin{abstract}
A B S T R A C T
Benthic oxygen fluxes, an established proxy for total organic carbon mineralization, were investigated in oligotrophic deep sea sediments. We used three different in situ technologies to estimate the benthic oxygen fluxes at an Arctic deep sea site (2500 m depth, HAUSGARTEN observatory) with limiting conditions of low oxygen gradients and fluxes, low turbulence and low particle content in the benthic boundary layer. The resolved eddy covariance turbulent oxygen flux $\left(-0.9 \pm 0.2(\mathrm{SD}) \mathrm{mmol} \mathrm{O}_{2} \mathrm{~m}^{-2} \mathrm{~d}^{-1}\right.$ ) compared well with simultaneous dissolved oxygen flux measurements carried out with a microprofiler $\left(-1.02 \pm 0.3(\mathrm{SD}) \mathrm{mmol} \mathrm{O}_{2} \mathrm{~m}^{-2} \mathrm{~d}^{-1}\right)$ and total oxygen uptake obtained by benthic chamber incubations $\left(-1.1 \pm 0.1\right.$ (SD) $\left.\mathrm{mmol} \mathrm{O}_{2} \mathrm{~m}^{-2} \mathrm{~d}^{-1}\right)$. The agreement between these different techniques revealed that microbial-mediated oxygen consumption was dominant at this site. The average benthic flux equals a carbon mineralization rate of $4.3 \mathrm{~g} \mathrm{C} \mathrm{m}^{-2} \mathrm{yr}^{-1}$, which exceeds the annual sedimentation of particulate organic matter measured by sediment traps.

The present study represents a detailed comparison of different in situ technologies for benthic flux measurements at different spatial scales in oligotrophic deep sea sediments. The use of eddy covariance, so far rarely used for deep sea investigations, is presented in detail.
\end{abstract}

(c) 2016 Elsevier Ltd. All rights reserved.

\section{Introduction}

Benthic oxygen uptake reflects the total turnover of organic material reaching the seafloor (Smith et al., 1983; Pfannkuche, 1993; Smith et al., 2013). Deep sea benthic communities are fueled by a relatively small amount of sinking organic matter $(<5 \%$ of surface production. e.g. Graf, 1989; Gooday and Turley, 1990; Smith et al., 2008), promoting a highly variable oxygen uptake between -0.1 and $-10 \mathrm{mmol} \mathrm{m}^{-2} \mathrm{~d}^{-1}$ (Glud (2008) and references therein). Polar deep-sea sediments represent the mid-lower end, with oxygen consumption rates on the order of $1 \mathrm{mmol} \mathrm{m}{ }^{-2} \mathrm{~d}^{-1}$ or lower (Sauter et al., 2001; Veit-Köhler et al., 2011). While deep sea sediments $(>1000 \mathrm{~m}$ ) make up the majority of the seafloor surface (Gage and Tyler, 1991), their role in regulating the global carbon cycle is still not clear (Smith et al. 2008, 2013).

\footnotetext{
* Corresponding author at: Institute F.-A. Forel, Earth and Environmental Sciences, Faculty of Sciences, University of Geneva, Geneva, Switzerland.

E-mail address: daphne.donis@unige.ch (D. Donis).
}

Irrespective of the applied technique, there is a general lack of prolonged and seasonal estimates of oxygen fluxes at the deep sea floor (Smith et al., 2008). This is mostly due to the technical challenges of performing in situ measurements at great depths, which are significantly more reliable than those obtained from retrieved sediment cores (Glud et al., 1994; Wenzhöfer and Glud, 2002). Yet benthic flux measurements covering longer time periods are extremely demanding in terms of operational costs and thus still not practicable, especially in areas with seasonal ice cover.

In situ oxygen flux measurements with state-of-the-art techniques (microprofilers, benthic chambers and eddy covariance (EC)) allow estimates of organic matter mineralization at the seafloor at different spatial scales. The first two traditional methods are well-known and extensively applied in the deep sea (e.g. Glud et al., 1994; Jahnke, 1996; Wenzhöfer and Glud 2002; Smith et al., 2008), while the later (EC) was only used once in deep sea environments (Berg et al., 2009).

Porewater oxygen microprofiles are used to measure the dissolved oxygen uptake (DOU, i.e. excluding fauna mediated flux) 
across the sediment water interface and the oxygen fine scale microdistribution within the sediment (Reimers, 1987; Gundersen and Jørgensen, 1990; Rasmussen and Jørgensen, 1992; Glud et al., 2005). Benthic chamber incubations track the decrease in oxygen concentration in an enclosed bottom water parcel over time, resolving the total oxygen uptake (TOU) over the chamber-isolated sediment section, including small fauna mediated fluxes (Smith 1978, Glud et al., 1994). Eddy covariance (EC) technique resolves the footprint integrated benthic exchange rates with a high temporal resolution without disturbing the surface or isolating portions of sediment and overlying water (Berg et al., 2003). EC measurements, therefore include the fauna mediated exchange as well as the dynamic seafloor-bottom water interactions (Kuwae et al., 2006; Glud et al., 2010; Hume et al., 2011; Reimers et al., 2012; Long et al., 2013; McGinnis et al., 2014).

Here we present in situ $\mathrm{O}_{2}$ flux measurements from an oligotrophic deep sea site (central station of HAUSGARTEN observatory, $2500 \mathrm{~m}$ water depth) using three methods, by which we were able to estimate both the oxygen exchange as well as the turbulent transport in the benthic boundary layer. We validate and present procedures for processing oxygen fluxes from oligotrophic environments where measurements are particularly challenging (low fluxes, weak turbulence and low backscatter for velocity measurements). The fluxes from EC, benthic chambers and microprofiler measurements are compared, and limitations and prospects are discussed. Finally we discuss the ecological implications of our findings for the study area.

\section{Materials and methods}

\subsection{Site description}

The HAUSGARTEN observatory (Soltwedel et al., 2005) is located in the Fram Strait (Fig. 1), a large channel ( $\sim 500 \mathrm{~km}$ wide) that separates northeast Greenland from the Svalbard archipelago. With a sill depth of ca. $2600 \mathrm{~m}$, this is the deep-water connection where heat and mass exchange take place between the North Atlantic and the Arctic Ocean (Manley, 1995; Fahrbach et al., 2001; Schauer et al., 2008). The hydrographic regime at HAUSGARTEN is characterized by the inflow of relatively warm, nutrient-rich Atlantic water into the central Arctic Ocean, and the outflow of less saline polar waters (East Greenland Current). Due to the heat exchange, the sea-ice cover in Fram Strait is variable, with permanently ice-covered areas in western parts, permanently ice-free areas in southeastern parts, and seasonally varying ice conditions in the central and northeastern parts of the Fram Strait (Vinje, $1977,1985)$, which also influences the export of organic matter to the seafloor (Bauerfeind et al., 2009). Despite the fact that the primary production export varies over a seasonal cycle, the overall amount of particulate organic material reaching the deep seafloor remains low (Bauerfeind et al., 2009; Forest et al., 2010). Combined with weak bottom turbulence, low particle concentrations are therefore expected in the bottom water. During the cruise PS 78 (ARK XXIV/2) on the research icebreaker RV Polarstern in July 2011, in situ benthic oxygen uptake measurements were performed at the central HAUSGARTEN station HG-IV (metadata: PS78/146-1 and PS78/147-1) in the central Fram Strait (Fig. 1; 79 $4.83^{\prime} \mathrm{N} 4^{\circ} 5.41^{\prime} \mathrm{E}$ ) at $2467 \mathrm{~m}$ water depth.

\subsection{Benthic oxygen flux measurements}

In situ benthic fluxes were measured with a suite of deep sea instruments covering several spatial scales, including benthic chambers (Jahnke and Christiansen, 1989; Pfannkuche, 1993; Tengberg et al., 1995; Wenzhöfer and Glud, 2002), a sediment

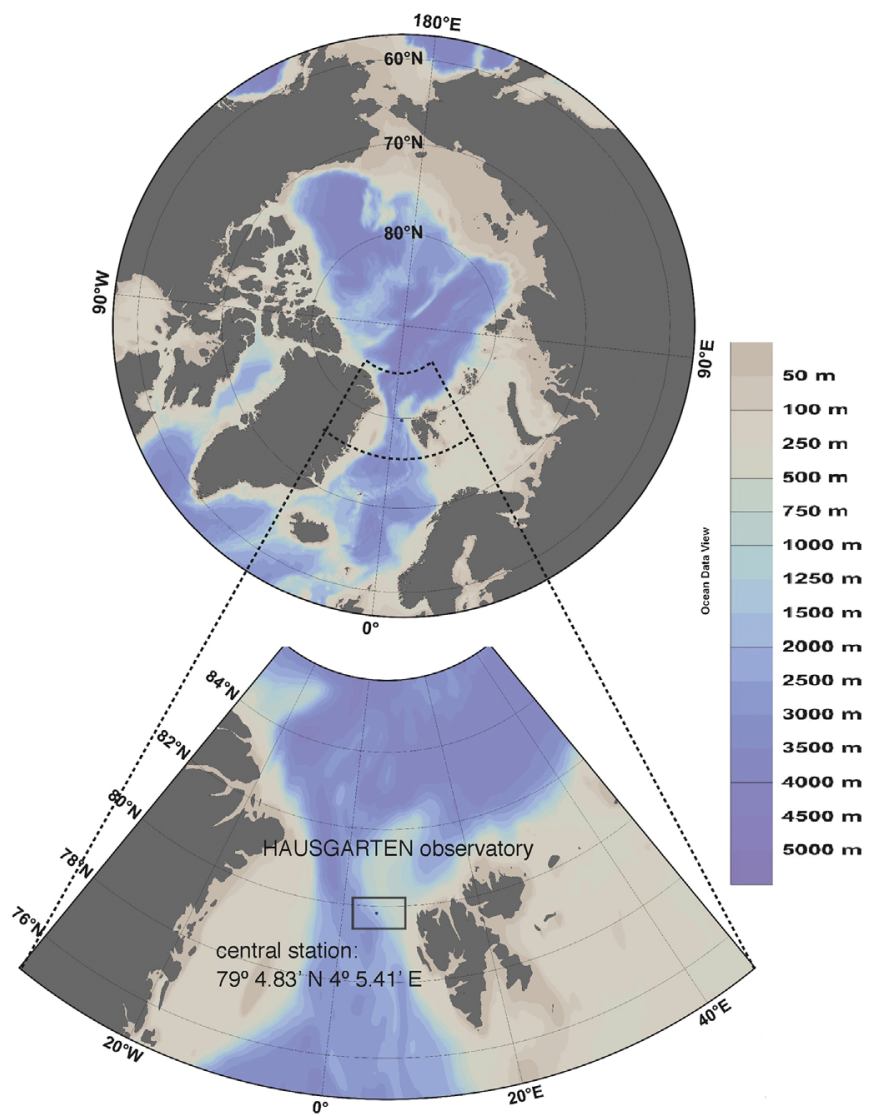

Fig. 1. Map of the area where the AWI deep sea long term observatory HAUS GARTEN is located (Schlitzer (2005), Ocean Data View, http://odv.awi.de). The point indicates the central station at $\sim 2500 \mathrm{~m}$ depth where benthic oxygen fluxes measurements where obtained.

microprofiler (Reimers et al., 1986; Glud et al., 1994; Wenzhöfer and Glud, 2002) and an aquatic eddy covariance (EC) system (Berg et al., 2003; McGinnis et al., 2011). The instruments were mounted on two autonomous benthic lander systems (Smith, 1978; Reimers, 1987; Witte and Pfannkuche, 2000) deployed next to each other (spacing $\sim 1 \mathrm{~km}$ ). One lander was equipped with the microprofiler unit, providing dissolved oxygen uptake (DOU) measurements, and the other lander was equipped with 3 benthic chambers together with the EC system, providing total oxygen uptake ( $\mathrm{TOU}_{\mathrm{CH}}$ and $\mathrm{TOU}_{\mathrm{EC}}$, respectively) data. The difference between TOU and DOU is commonly attributed to faunal-mediated consumption (e.g. Glud et al. 2003), including the respiration activity of the organisms and the increase of oxygen penetration in deeper sediment layers through their borrows (e.g. Grenz et al., 2003: Rabouille et al., 2003). A heterogeneous sediment microtopography can also contribute to the difference between DOU and TOU derivations (Glud (2008) and references therein).

\subsection{1. $\mathrm{O}_{2}$ microprofiles}

High-resolution $\mathrm{O}_{2}$ profiles were measured with five Clark-type oxygen microelectrodes (Revsbech, 1989) mounted on an autonomous $x-y-z$ microprofiler module. The oxygen distribution across the sediment-water interface was measured with a depth resolution of $150 \mu \mathrm{m}$ to a sediment depth of $\sim 7 \mathrm{~cm}$. The sensors repeated sampling by horizontal repositioning of the module after each profile resulting in 16 vertical cycles within an area of $625 \mathrm{~cm}^{2}$. Because of small drop stones on the sediment surface, four electrodes unfortunately broke during the first vertical profiling. The surviving sensor provided profiles with a horizontal spacing of $4.5 \mathrm{~cm}$ and $7 \mathrm{~cm}$ ( $\mathrm{x}$ - and $\mathrm{y}$-axis, respectively). The 
microsensors were calibrated with a two-point calibration using the $\mathrm{O}_{2}$ concentration in the bottom water determined by Winkler titration (Grasshoff et al., 1983) and on-board signals recorded in anoxic, dithionite-spiked bottom water at in situ temperature.

Diffusive fluxes were calculated by two different methods: interface-gradient by applying Fick's first law of diffusion (e.g., Jørgensen and Revsbech, 1985; Rasmussen and Jsrgensen, 1992) and PROFILE Software (Berg et al., 1998). The diffusion coefficient of $\mathrm{O}_{2}$ in seawater was corrected for salinity and temperature (Li and Gregory, 1974). Note that for modeling the profiles and fluxes with the software PROFILE sensor data had to be reduced to 125 data points, subsequently lowering the vertical resolution of the measured profile.

\subsubsection{Benthic chamber incubations}

The $\mathrm{TOU}_{\mathrm{Ch}}$ at the sediment-water interface was determined in situ with three square benthic chambers $(20 \times 20 \mathrm{~cm}$; Witte and Pfannkuche, 2000) mounted on a benthic lander. After landing at the seafloor and a waiting period of $4 \mathrm{~h}$, the chambers were driven into the sediment for a pre-programmed distance aiming for an enclosed water body height of $10-15 \mathrm{~cm}$. The overlying water was gently stirred at $8 \mathrm{rpm}$ to avoid stagnation. Changes in oxygen concentration were monitored over time by optodes (Aanderaa, Norway) at an interval of 10 min over an incubation period of $48 \mathrm{~h}$. At the end of the incubation, a blind sealed the chambers at the bottom to enclose the incubated sediment and the lander was retrieved. Onboard, the height of the overlying water body was measured with a ruler at 6-8 positions within each chamber. The $\mathrm{TOU}_{\mathrm{Ch}}$ flux $\left(\mathrm{mmol} \mathrm{O}_{2} \mathrm{~m}^{-2} \mathrm{~d}^{-1}\right)$ was calculated from the initial linear decrease in $\mathrm{O}_{2}$ concentration versus time (first $30 \mathrm{~h}$ ) in the enclosed overlying water body (Glud et al., 1994).

\subsubsection{EC instrument and deployment}

The EC system consisted of a Nortek acoustic Doppler velocimeter (ADV, Nortek, Norway) for the measurement of the three velocity components $(\mathrm{x}, \mathrm{y}, \mathrm{z})$ of the bottom water and a Clark type $\mathrm{O}_{2}$ microelectrode (Revsbech, 1989) connected to an amplifier for the measurement of dissolved oxygen concentration (Berg et al., 2003), both powered with an internal battery.

The EC system was fixed to the chamber lander (Fig. 2) so that dissolved $\mathrm{O}_{2}$ and velocity measurements took place at $15 \mathrm{~cm}$ above the seafloor. The microelectrode tip and the ADV sampling volume were separated by a distance of $\sim 0.8 \mathrm{~cm}$. The amplitude in the
$A D V$ recordings was checked to ensure there was no interference between the oxygen sensor tip and the ADV readings. The ADV was programmed for working in continuous mode with a sampling frequency of $32 \mathrm{~Hz}$, a nominal velocity of $0.1 \mathrm{~ms}^{-1}$, and standard settings for aquatic EC applications: a transmit length of $4.0 \mathrm{~mm}$, sampling volume $14.9 \mathrm{~mm}$ and receive length $0.01 \mathrm{~m}$.

The position of the two sensors with respect to the current direction was inferred by the heading of the ADV compass. A fin at the opposite side of the lander frame initially oriented the EC sensors towards the main current flow. However, during the $11 \mathrm{~h}$ measuring period, the current direction varied, as discussed below. The fast responding $\mathrm{O}_{2}$ microelectrode (tip diameter $15 \mu \mathrm{m}$, response time $<0.2 \mathrm{~s}$ ) was calibrated at in situ conditions (salinity and temperature) against oxygen saturated and anoxic seawater (Gundersen et al., 1998).

2.2.3.1. EC flux analysis. EC fluxes (equal to $\mathrm{TOU}_{\mathrm{EC}}$ ) are derived using the temporal average of the covariance of the instantaneous fluctuating components of vertical velocity and the measured oxygen concentration ( $\mathrm{w}^{\prime}$ and $\mathrm{C}^{\prime}$ respectively).

ECflux $=\overline{w^{\prime} C^{\prime}}$.

The fluctuating components are resolved by subtracting the average velocity $\left(\overline{W^{\prime}}\right)$ and $\mathrm{O}_{2}$ concentration $\left(\overline{C^{\prime}}\right)$ from the measured time series. A negative covariance between $w^{\prime}$ and $C^{\prime}$ indicates a negative flux and a net transport of $\mathrm{O}_{2}$ towards the sediment while positive fluxes would correspond to a net transport of $\mathrm{O}_{2}$ from the sediment to the water column if applied to phototrophic sediments (Berg et al., 2003).

A multistep process was used to extract the time series from the raw data (for details see http://sohfea.dfmcginnis.com/ and McGinnis et al. (2014)). The $32 \mathrm{~Hz}$ recordings were averaged to $4 \mathrm{~Hz}$ to reduce the signal to noise ratio, and to increase the ease of handling the data set. Oxygen data were despiked using a running mean on $300 \mathrm{~s}$ length and a standard deviation multiple equal to 5. Data points that fall outside the standard deviation times the multiple are removed and replaced by the running mean. Spike removal for velocity was based on a vertical acceleration threshold of $0.3 \mathrm{~m} \mathrm{~s}^{-1}$. Removed spikes are replaced by linear interpolation of neighboring data (based on Goring and Nikora (2002)).

The routine removes data flagged as bad before averaging is performed. Data are flagged based on user-specified signal-tonoise ratio (SNR) and beam correlation (CORR). Elgar et al. (2005)
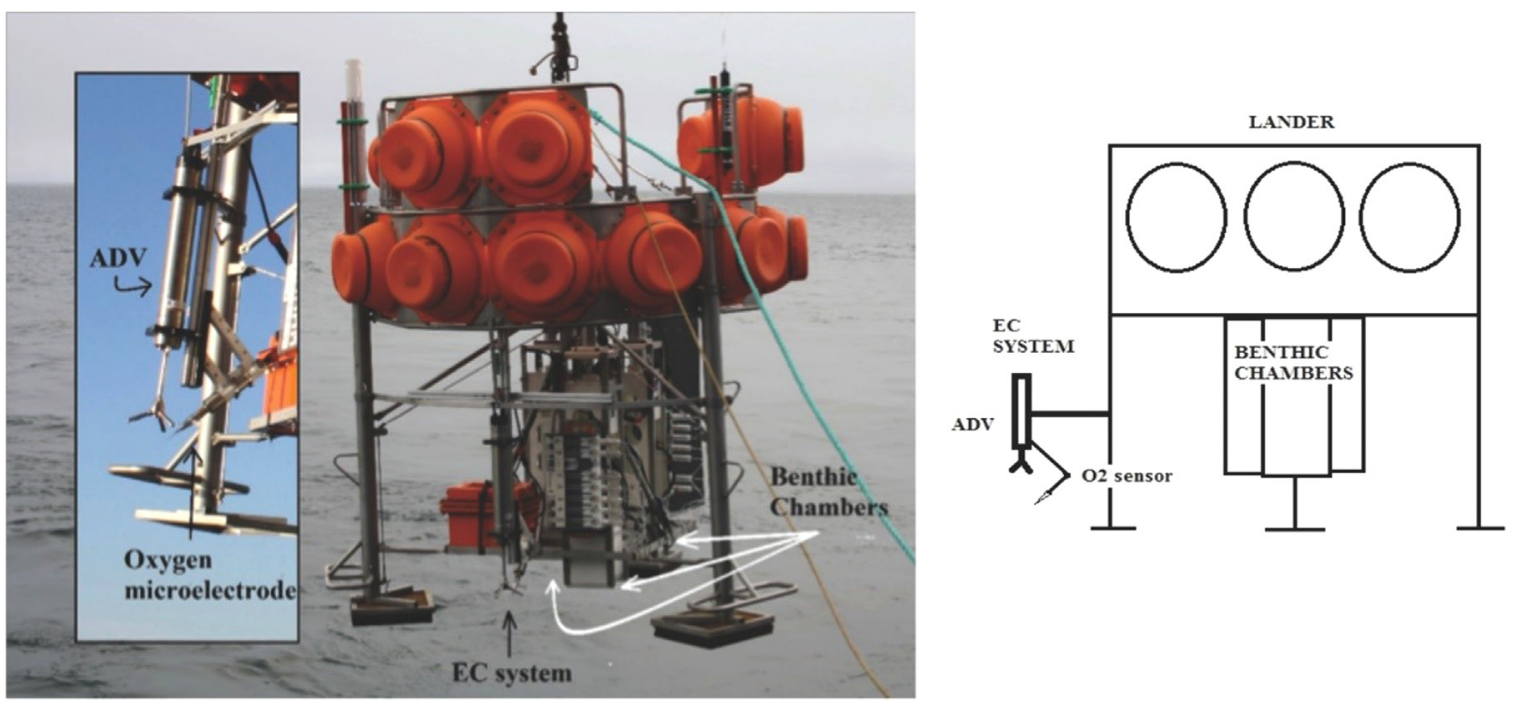

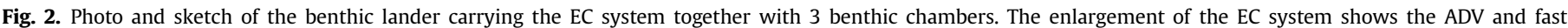
responding oxygen microelectrode attached to the lander frame. 
proposed to exclude ADV data with CORR values lower than 60\% (for our settings). However, weak scatters and low particle concentrations can reduce the return signal strength, therefore, we replaced data with a SNR $<1$ and beam correlation $<50 \%$ (see Section 4.2.1). These data were not included in the bin averaging from 32 to $4 \mathrm{~Hz}$.

Spectral analysis was performed on the vertical velocity to determine the range of turbulent eddy timescales (McGinnis et al., 2008; Lorrai et al., 2010). It was verified that the turbulent structures had timescales between $\sim 1$ and $100 \mathrm{~s}$ We then separated the time series into the average and fluctuating components (Reynolds decomposition) (Lee et al., 2004) using a window size of 5 min, which was expected to include all turbulent eddy contributions. This was later confirmed by the cumulative cospectra of $\mathrm{w}^{\prime} \mathrm{C}^{\prime}$ (discussed below), which confirmed that the vertical oxygen eddy flux includes turbulent structures with timescales between $\sim 1$ and $100 \mathrm{~s}(1-0.01 \mathrm{~Hz})$.

As both sensors are slightly spatially separated, the lag time between the time series $\mathrm{w}^{\prime}$ and $\mathrm{C}^{\prime}$ depends on the distance between the ADV velocity sampling volume and the $\mathrm{O}_{2}$ sensor tip, the turbulent regime, the velocity direction, and the response time of the $\mathrm{O}_{2}$ microelectrode (McGinnis et al., 2008; Lorrai et al., 2010; Donis et al., 2015). Therefore the time series $\mathbf{w}^{\prime}$ and $\mathrm{C}^{\prime}$ were crosscorrelated for each measuring interval (15 min) allowing stepwise time shifts of $0.25 \mathrm{~s}$ (for a maximum of $\pm 4 \mathrm{~s}$ ) (Holtappels et al., 2013). The time series shifting was allowed until the highest correlation coefficient for each 15 min measuring interval was found. If the applied time shift was coherent with the distance between sampling volumes, the response time of the oxygen sensor and the flow magnitude, then the shift was assumed to correspond to the correct flux estimation. For example, with a sampling volume distance of $0.8 \mathrm{~cm}$ and an $\mathrm{O}_{2}$ response time of $0.2 \mathrm{~s}$, we obtain a time shift of $0.4 \mathrm{~s}$ during a steady flow velocity of $3.7 \mathrm{~cm} \mathrm{~s}^{-1}$, which is close to a theoretical time shift of $0.5 \mathrm{~s}$ The obtained fluxes were then evaluated by calculating the probability of obtaining the same correlation, i.e. the same flux, from random data sets (corrcoef function in Matlab 7.10.0, R2010a). The significance threshold was set at 0.05 .

\section{Results}

3.1. Benthic oxygen fluxes: microprofiles, chamber incubations and eddy covariance

All fluxes showed good agreement, with a total average of $1.0 \pm 0.4(\mathrm{SD}, \mathrm{N}=49) \mathrm{mmol} \mathrm{O}_{2} \mathrm{~m}^{-2} \mathrm{~d}^{-1}$. The fluxes calculated for each method are summarized in Table 1 , and described in detail below.

\subsubsection{Microprofiles}

Diffusive fluxes were calculated from 16 oxygen microprofiles covering an area of $625 \mathrm{~cm}^{2}$. All measured profiles showed an oxygen penetration depth $>6 \mathrm{~cm}$ (Fig. 3). Fluxes were calculated by linear fitting of the oxygen gradient in the diffusive boundary layer $\left(\mathrm{J}_{\mathrm{grad}}\right)$ and resulted in an average diffusive oxygen uptake of

Table 1

Summary of oxygen fluxes obtained at HAUSGARTEN central station $(2500 \mathrm{~m}$ depth) with microprofiler, benthic chambers and eddy covariance, with relative date and measurement duration.

\begin{tabular}{|c|c|c|c|}
\hline Method & Flux $\left(\operatorname{mmol~} \mathrm{O}_{2} \mathrm{~m}^{-2} \mathrm{~d}^{-1}\right)$ & Date & Duration \\
\hline Microprofiler & $-1.02 \pm 0.3(\mathrm{sd}, \mathrm{N}=16)$ & 17-19 July 2011 & $49 \mathrm{~h}$ \\
\hline Benthic chambers & $-1.1 \pm 0.1(\mathrm{sd}, \mathrm{N}=3)$ & 18-19 July 2011 & $48 \mathrm{~h}$ \\
\hline Eddy covariance & $-0.9 \pm 0.2(\mathrm{sd}, \mathrm{N}=30)$ & 17 July 2011 & $11 \mathrm{~h}$ \\
\hline
\end{tabular}

$-1.02 \pm 0.3(\mathrm{SD}) \mathrm{mmol} \mathrm{O}_{2} \mathrm{~m}^{-2} \mathrm{~d}^{-1}$. The alternative flux calculation performed with PROFILE software $\left(\mathrm{J}_{\text {int }}\right)$, assuming that molecular diffusion was the dominant transport process, showed good agreement with an average DOU of $-0.96 \pm 0.2$ (SD) $\mathrm{mmol} \mathrm{O}_{2} \mathrm{~m}^{-2} \mathrm{~d}^{-1}$. Both methods revealed some variability in the upper sediment layer indicating a heterogenic distribution of organic matter (Fig. 3).

\subsubsection{Benthic chambers}

$\mathrm{TOU}_{\mathrm{Ch}}$ was estimated from three benthic chambers incubating a sediment area of $400 \mathrm{~cm}^{2}$ over $48 \mathrm{~h}$. From the decrease in oxygen over time $\left(\sim 12 \mu \mathrm{mol} \mathrm{L}^{-1} \quad \mathrm{O}_{2}\right.$ in $\left.30 \mathrm{~h}\right)$ an average $\mathrm{TOU}_{\mathrm{Ch}}$ of $-1.2 \pm 0.3(\mathrm{SD}) \mathrm{mmol} \mathrm{O}_{2} \mathrm{~m}^{-2} \mathrm{~d}^{-1}$ was calculated (Fig. 4).

\subsubsection{Eddy covariance}

The 11-h EC measurement was performed between 2:00 and 13:00, when the current velocity varied between 0.2 and $4.4 \mathrm{~cm} \mathrm{~s}^{-1}$ with a mean of $2.0 \mathrm{~cm} \mathrm{~s}^{-1}$ (Fig. 5A). The $\mathrm{O}_{2}$ concentration measured by the microelectrode (data not shown) decreased slightly during the $11 \mathrm{~h}$ deployment, from 0.305 to $0.296 \mathrm{mmol} \mathrm{L}^{-1}$, which was most probably caused by an electronic drift in the signal as discussed in Section 5.2.3. Until 10:00 the bottom water current was directed towards the EC system, i.e. the EC system was upstream of the lander (Fig. $5 \mathrm{~B}$ ), and the $\mathrm{EC} \mathrm{O}_{2}$ sensor was downstream of the ADV measuring volume. After 10:00, abrupt changes in the current direction were associated to oscillations in the current magnitude ( $\max \pm 1 \mathrm{~cm} \mathrm{~s}^{-1}$ ). Given the high uncertainty associated with the last $3 \mathrm{~h}$ of the measurement (see Sections 5.2.3 and 5.2.4), only the first $8 \mathrm{~h}$ were considered as a reliable representation of the benthic oxygen consumption, resulting in an average EC flux of $-0.9 \pm 0.2(\mathrm{SD}) \mathrm{mmol} \mathrm{O}_{2} \mathrm{~m}^{-2} \mathrm{~d}^{-1}$ (Fig. 5C).

\section{Discussion}

Resolving benthic oxygen fluxes at oligotrophic deep sea sites like the Arctic HAUSGARTEN station HG-IV (2500 m water depth) is challenging given that the sediment community activity is rather low and settling organic matter often unevenly distributed. Applying state-of-the-art in situ methods (microprofiles, benthic chamber incubations, eddy covariance) to quantify oxygen consumption rates provides information at different spatial and temporal scales but may also suffer from specific drawbacks, mostly when approaching their resolution limits. In the following sections we assess the results and discuss limits and capabilities of these methods when applied to deep sea oligotrophic sediments.

\subsection{Microprofiles and benthic chambers}

An oxygen uptake in the order of $1 \mathrm{mmol} \mathrm{m}^{-2} \mathrm{~d}^{-1}$ corresponds to weak oxygen gradients at the sediment water interface (SWI). Consequently, the diffusive boundary layer and the associated linear gradient were not always obviously detectable in our data. Although from most of the profiles the SWI and diffusive boundary layer above could be visually identified from the distinct change in concentration, some profiles did not show a clear change in concentration. In this case the diffusive flux for the interface gradient method was then estimated using 3-4 successive oxygen values of the $\mathrm{O}_{2}$ gradient at the intersection with the constant signal of the mixed bottom water. This can, however, lead to a slight over- or underestimation of the flux, perhaps resulting in some of the observed variability (30\%). Nevertheless, flux values obtained by the PROFILE software, which take into account the overall oxygen profile, showed similar results (6\% difference) and similar variability within the 16 fluxes (20\%). This suggests some small-scale 


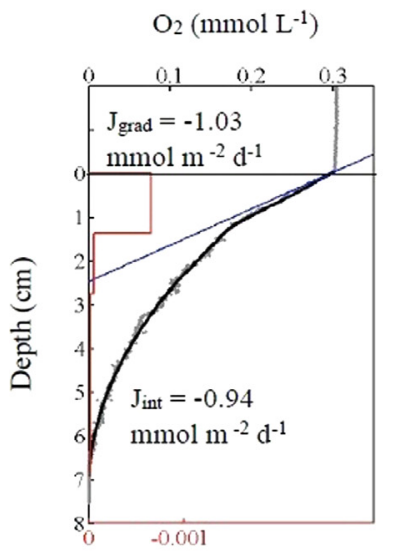

$\mathrm{O} 2$ cons. (nmol cm-3 $\mathrm{s}^{-1}$ )
$\mathrm{O}_{2}(\mathrm{mmol} \mathrm{L}-1)$

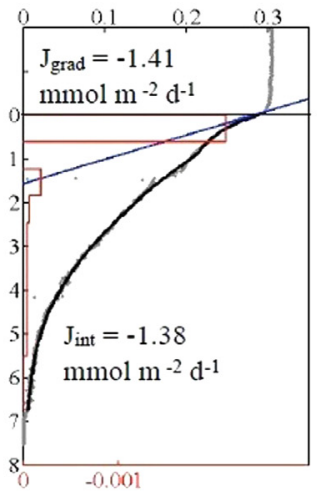

$\mathrm{O} 2$ cons. (nmol cm-3 $\left.\mathrm{s}^{-1}\right)$
$\mathrm{O}_{2}(\mathrm{mmol} \mathrm{L}-1)$

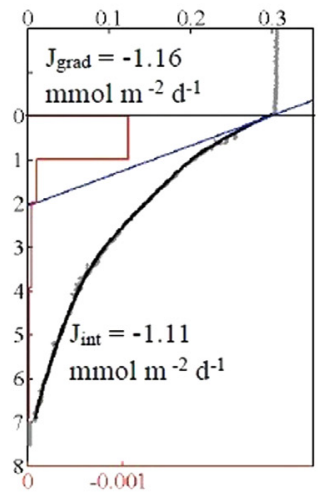

$\mathrm{O} 2$ cons. (nmol cm-3 $\mathrm{s}^{-1}$ )
$\mathrm{O}_{2}\left(\mathrm{mmol} \mathrm{L}^{-1}\right)$

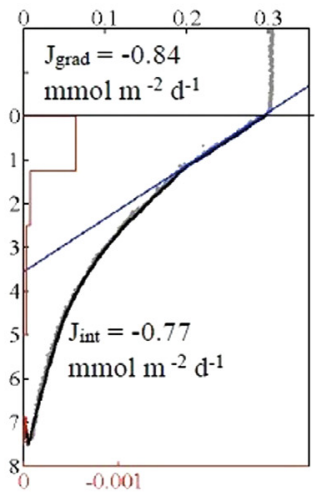

$\mathrm{O} 2$ cons. (nmol cm-3 $\mathrm{s}^{-1}$ )
$\mathrm{O}_{2}\left(\mathrm{mmol} \mathrm{L}^{-1}\right)$

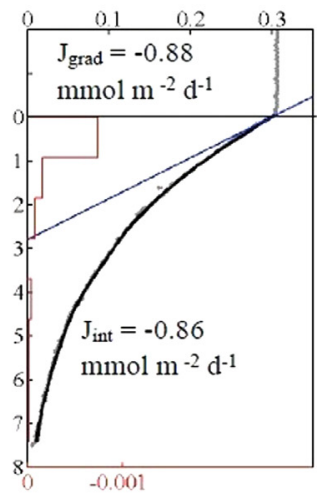

$\mathrm{O} 2$ cons. (nmol cm-3 $\mathrm{s}^{-1}$ )

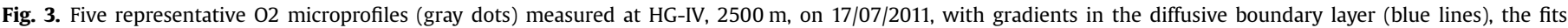
obtained by the profile interpretation software PROFILE (black lines), 02 consumption rates as a function of depth (red step curves), and flux estimates ( $\mathrm{J}_{\text {int }}$ and $\mathrm{J}_{\text {grad }}$ ).

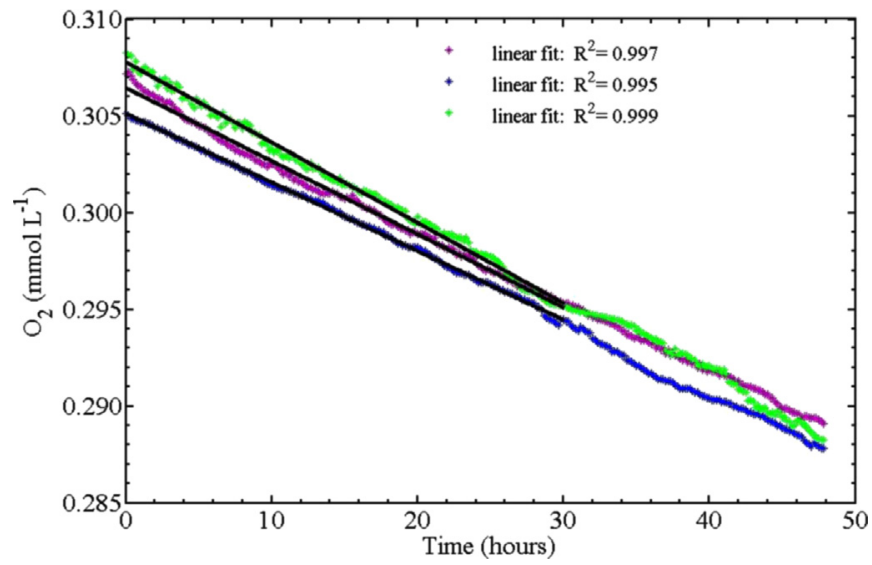

Fig. 4. $\mathrm{O}_{2}$ concentration (symbols) in the chamber as measured during the $48 \mathrm{~h}$ deployment (HG-IV, $2500 \mathrm{~m}$, on 17/07/2011). TOU was calculated by linear fit over the first $30 \mathrm{~h}$ (black lines).

spatial heterogeneity in oxygen consumption processes. However such DOU variability was observed within $\sim 625 \mathrm{~cm}^{2}$, and is therefore most likely linked to microtopography driving local deposition of organic matter rather than to larger scale features (e.g. macrofauna activity). This is also supported by the varying volume-specific $\mathrm{O}_{2}$ consumption rates at the sediment water interface, while deeper consumption rates and oxygen penetration was rather similar among profiles (Fig. 3). Thus the main advantage for using pore water oxygen microprofiles is the high vertical resolution detailing the oxygen distribution in the sediment and the identification of distinct zones of microbial activity. For deep sea sediments it is however common to find oxygen penetration depths in the order of centimeters and in oligotrophic areas (as Polar Regions) even tens of centimeters (Sachs et al., 2009). Therefore, besides some technical difficulties in detecting the sediment water interface, the potential downside for the microprofiling method in deep sea regions is that profiles may not reach the anoxic layer and that each single profile may take up to several hours to perform, leading to a limited temporal and spatial information.

Benthic chamber incubations integrate the oxygen consumption rate over a larger area, however difficulties in measuring low benthic fluxes can arise because of the longer period of incubation needed to produce a measurable decrease in $\mathrm{O}_{2}$ concentration. Therefore one has to assume constant hydrodynamics for incubation periods $>30 \mathrm{~h}$, which are often required in deep sea sediments to obtain a measureable change in oxygen concentration. The linear and constant decrease in oxygen concentration, as seen in our three incubations (Fig. 4) and the good linear fit provide reproducible and reliable total flux estimates. However, in order to increase the number of replicates, several chambers have to be deployed in parallel or successively. Nevertheless, the advantage of chamber incubations is that fluxes can be related directly to the benthic community and organic matter present in the retrieved sediment.

\subsection{Eddy covariance}

EC instrumentation must be able to reasonably resolve the fluxrelevant scales, which depend on the local dissolved oxygen gradients and turbulence (see e.g. Lorrai et al., 2010). The technique's challenge in deep sea environments is thereby the resolution of the two measured components (velocity and oxygen) under unfavorable conditions of weak turbulence and low oxygen gradients, which may produce turbulent fluctuations $\left(\mathrm{w}^{\prime} \mathrm{C}^{\prime}\right)$ that are too small to be resolved (e.g. Brand et al., 2008).

Procedures to compute and assess EC fluxes need to be explained in detail given the substantial difference between the EC method and the more traditional in situ benthic flux measurement techniques. Furthermore most of the EC measurements were so far performed at coastal or shelf ecosystems with a resolved $\mathrm{O}_{2}$ flux ranging between 10 and $400 \mathrm{mmol} \mathrm{O}_{2} \mathrm{~m}^{-2} \mathrm{~d}^{-1}$ (e.g. McGinnis et al., 2008; Chipman et al., 2012; Berg et al., 2013). The only EC deployment on deep sea sediments was carried out by Berg et al. (2009) in Sagami Bay (Japan) at $1450 \mathrm{~m}$ depth, revealing a benthic oxygen consumption of approximately $-1.5 \mathrm{mmol} \mathrm{O}_{2} \mathrm{~m}^{-2} \mathrm{~d}^{-1}$.

We will thus describe the major issues/challenges that need to be carefully addressed when using EC. Some of the presented assessments are specific (but not exclusive) for oligotrophic deep sea sediments (low particles content, weak $\mathrm{O}_{2}$ gradients) while others are of general concern (transient conditions, $\mathrm{O}_{2}$ sensor stirring sensitivity).

\subsubsection{Low particles content and ADV beam correlation threshold}

Low particulate matter in the bottom water, which is often the case in oligotrophic waters, can compromise the quality of the ADV velocity data, as these particles are needed to reflect the acoustic signal. Weak scatters, indicated by low beam correlations (Cabrera et al., 1987; Lhermitte and Lemmin 1994), can reduce the ADV return signal strength to the level of background noise (Elgar et al., 2005) and lead to inaccurate velocity estimates (Zedel et al., 

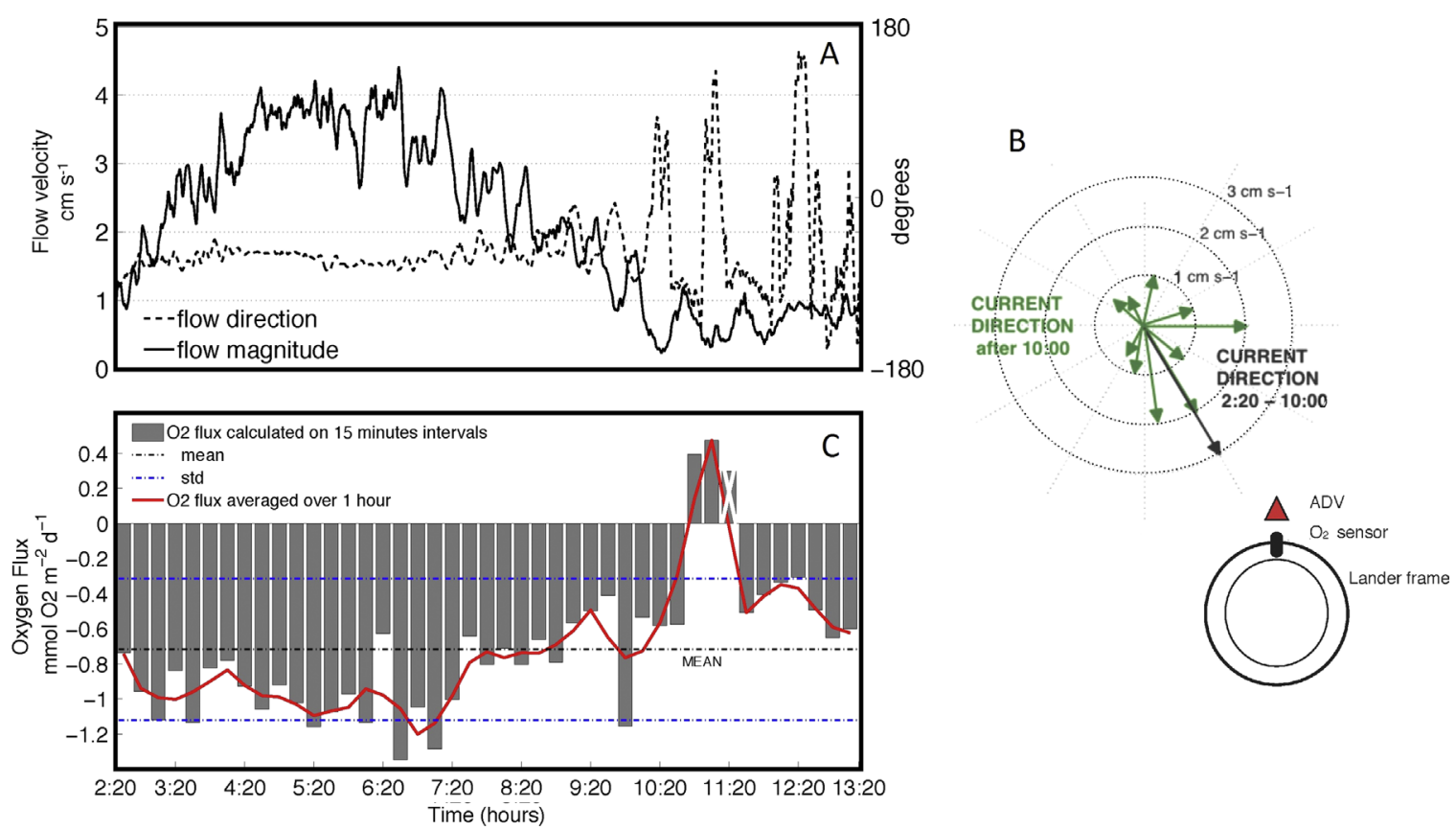

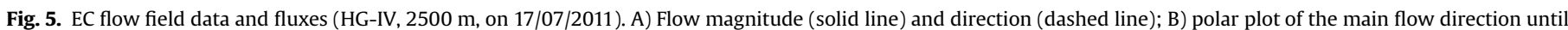

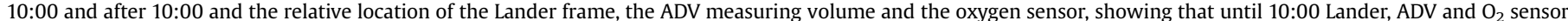

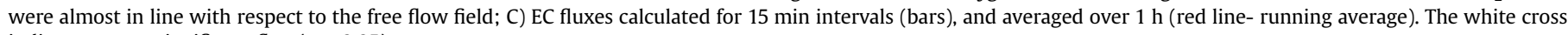
indicates a non-significant flux ( $p>0.05)$.

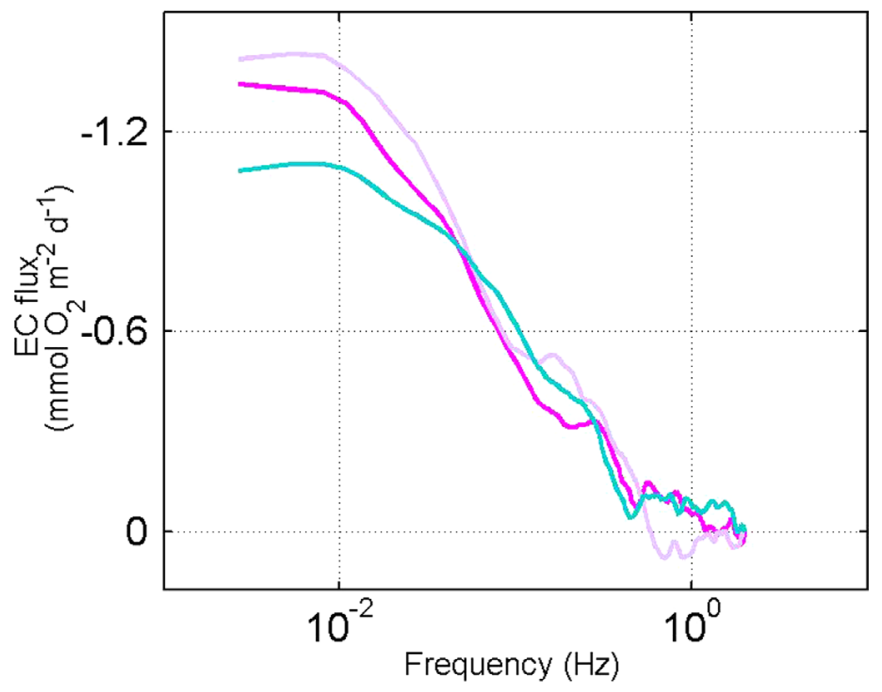

Fig. 6. Cumulative (co)spectra of $\mathrm{w}^{\prime} \mathrm{C}^{\prime}$ for three representative time intervals (between 5:00 and 7:30) showing the contribution of turbulent eddies to the vertical oxygen transport between 0.2 and $0.01 \mathrm{~Hz}(5-100 \mathrm{~s})$. The (co)spectrum also indicates a $\mathrm{O}_{2}$ flux of $\sim 1.2 \mathrm{mmol} \mathrm{O}_{2} \mathrm{~m}^{-2} \mathrm{~d}^{-1}$.

1996). The ADV correlation signal (ranging from 0 to 1.0 ) is therefore used to diagnose data quality (Zedel et al., 1996; SonTek, 2004). According to Elgar et al. (2005), with a sampling frequency of $32 \mathrm{~Hz}$ and a maximum capability for the ADV to sample at $64 \mathrm{~Hz}$ (capability of the ADV in the present study), the recommended minimum beam correlation (CORR) threshold is $60 \%$. However, when applying this threshold to our data, we could verify that while filtering from 32 to $4 \mathrm{~Hz}$ and replacing the violations by interpolation, more than $50 \%$ of the bins (composed by 8 data points) had to be replaced entirely. Therefore we lowered the CORR threshold to 50\%. Applying this threshold to our data set increased the number of bins that had at least one original value to $70 \%$, allowing a more robust interpolation. The density (co)spectrum of the fluctuating components $\left(w^{\prime} C^{\prime}\right)$ verified that after the down-sampling to $4 \mathrm{~Hz}$, the signal still resolved the contributing turbulence range, i.e. the scales that play a dominant role in energy and momentum transfer in the frequency domain.

\subsubsection{Electronic noise and small $\mathrm{O}_{2}$ fluctuations}

Extremely small fluctuations of $\mathrm{O}_{2}$ concentrations at the sediment water interface may be hard to detect with EC measurements if they approach the noise level of the microelectrode. The expected turbulent $\mathrm{O}_{2}$ fluctuations depend on the local $\mathrm{O}_{2}$ gradient and turbulence. Applying the sediment $\mathrm{O}_{2}$ uptake measured from microprofiles $\left(-1.02 \mathrm{mmol} \mathrm{O}_{2} \mathrm{~m}^{-2} \mathrm{~d}^{-1}\right)$, the magnitude of $\mathrm{O}_{2}$ fluctuations were estimated based on the turbulent velocities (as in Lorrai et al. (2010)). With a current velocity at $1 \mathrm{~m}$ above the seafloor of $\sim 0.03 \mathrm{~m} \mathrm{~s}^{-1}$ and a bottom friction coefficient for muddy sediments of 0.002 , the expected $\mathrm{O}_{2}$ fluctuations for our site are $\sim \pm 0.01 \mathrm{mmol} \mathrm{m}^{-3}$. This magnitude falls within the noise range of the used microelectrode $\left( \pm 0.06 \mathrm{mmol} \mathrm{m}^{-3}\right)$ calculated as the standard deviation of the difference of two consecutive data points of the measured $\mathrm{O}_{2}$ concentration (Lorrai et al., 2010). However, electronic noise is by definition randomly distributed around the mean and therefore should not significantly correlate with the vertical velocity fluctuations (Berg et al., 2009). Furthermore, the cumulative cross-spectral density (i.e. cumulative cospectrum) of $C^{\prime} \mathbf{w}^{\prime}$ (Fig. 6) indicates that the measurement consistently represents all eddy structures contributing to the vertical turbulent flux showing no evident contributions at frequencies above $0.2 \mathrm{~Hz}$, as expected in similar settings (Lorrai et al., 2010).

Likewise, fluxes produced by random noise would result in non-significant correlations, while in our data set the $15 \mathrm{~min}$ averaged EC fluxes are all statistically significant except for one (Fig. 5C). The significance of the correlation was tested by calculating the probability of obtaining the same correlation, i.e. the same flux, from random data sets. The significance of the calculated EC-fluxes as function of the flux magnitude is presented in Fig. 7 and illustrates the level of uncertainty. Even though fluxes were still significant, the probability for a random correlation increased when fluxes fell between $\pm 0.4 \mathrm{mmol} \mathrm{O}_{2} \mathrm{~m}^{-2} \mathrm{~d}^{-1}$. This 


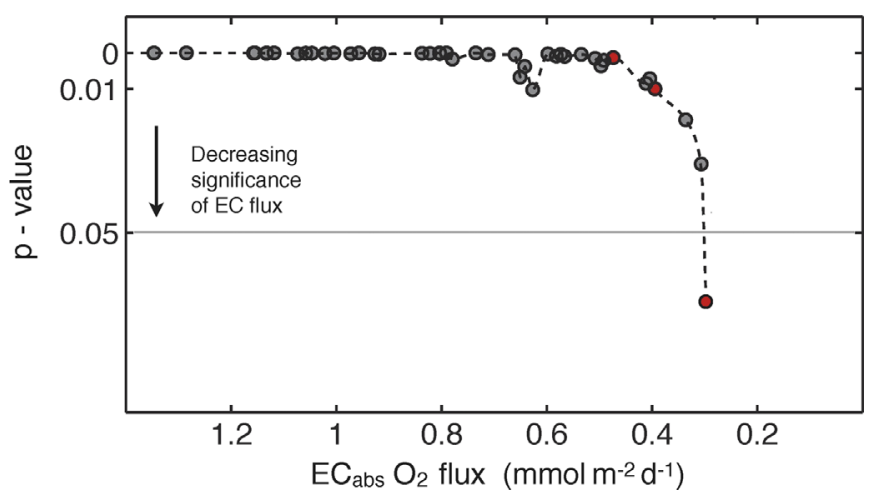

Fig. 7. Magnitude of the EC fluxes (absolute values on $x$ axis) plotted against their significance (y axis) suggesting increasing uncertainties related to fluxes between $\pm 0.4 \mathrm{mmol} \mathrm{O}_{2} \mathrm{~m}^{-2} \mathrm{~d}^{-1}$. Positive fluxes are indicated by red circles.

coincided with an unstable flow regime where the current direction varied between 60 and $120^{\circ}$ (Fig. 5A), and with flow velocities $<1 \mathrm{~cm} \mathrm{~s}^{-1}$, friction velocities $<1.5 \times 10^{-3} \mathrm{~m} \mathrm{~s}^{-1}$ and turbulence levels $<2.5 \mathrm{~mm} \mathrm{~s}^{-1}$ (defined as the standard deviation of the vertical velocity). Therefore we excluded the last $3 \mathrm{~h}$ from the average, even though they were still statistically significant. This may suggest that for EC deployments where $\mathrm{O}_{2}$ uptake is not expected to experience rapid changes (as in abyssal plains), it may be a good practice to examine the p-values trend, rather than considering only the arbitrary 0.05 or 0.01 threshold. The trend of significant fluxes would serve as an indicator for increasing level of uncertainties that in our case are determined by the low turbulence, the current direction changes, and - most plausible - the flow interference with the lander frame.

\subsubsection{Transient conditions}

Despite the increasing application of EC in the field, only a few studies have recommended procedures to detect and avoid erroneous fluxes (Holtappels et al., 2013; Rheuban and Berg, 2013; Donis et al., 2015). Inaccurate flux estimates can be attributed to natural processes, the deployment setting or to sensors and instrument design. Non-steady state conditions with respect to the $\mathrm{O}_{2}$ concentration or the current velocity, for instance, may induce erroneous fluxes that are not related to the benthic uptake (Holtappels et al., 2013). In our case the $\mathrm{O}_{2}$ concentration measured by the microelectrode decreased constantly during our 11-h deployment, from 0.305 to $0.296 \mathrm{mmol} \mathrm{L}^{-1}$ ). This very slight decrease (3\%) however was decoupled from current velocity and direction and was not observed with background measurements obtained by the profiling $\mathrm{O}_{2}$ sensors, which show constant concentrations. This makes it very likely that the signal decrease is caused by drift of the electrochemical sensor.

Contrarily, the increase of current velocity from 1 to $4 \mathrm{~cm} \mathrm{~s}^{-1}$ in the first $4 \mathrm{~h}$ and the subsequent decrease back to $1 \mathrm{~cm} \mathrm{~s}^{-1}$ over the next $4 \mathrm{~h}$ could potentially induce an additional flux that is not related to the benthic uptake (Holtappels et al., 2013). The correlation between current velocity and $\mathrm{O}_{2}$ flux was calculated over the first $8 \mathrm{~h}$, and could explain $20 \%$ of the flux variability $\left(\mathrm{R}^{2}=0.2\right)$. However, the EC flux was measured at both accelerating and decelerating velocities so that any flux contribution from non-steady state velocities cancels out when calculating the average EC flux. Consequently, the flux bias is negligible when averaging over the $8 \mathrm{~h}$.

Doubtlessly, the variable features observed in the flow direction time series from 10:00 on indicate that the main current shifted to an opposite direction, meaning that it was disturbed by the lander frame before flowing through the EC measurement point. This likely led to a non-uniform boundary layer, affecting the reliability of the covariance between $\mathrm{w}^{\prime}$ and $\mathrm{C}^{\prime}$. Furthermore the erratic change in flow direction may have induced a periodic forcing which, in case of enclosed water bodies, was proven to promote deviations of the structure and the dynamics of the bottom boundary layer from the classical law-of-the-wall theory (Lorke et al., 2003).

Overall the EC fluxes seem to be mainly affected by the abrupt changes in current direction, accompanied with water velocity magnitudes below $1 \mathrm{~cm} \mathrm{~s}^{-1}$ that may have enhanced the interference with the lander. Possibly, besides the interference between the flow field and the lander, the low and unsteady current velocities during this measurement period, coupled with small $\mathrm{O}_{2}$ fluctuations, brought the EC technique to its limit of detection, as was shown in other EC studies (Brand et al., 2008).

\subsubsection{Stirring sensitivity of electrochemical $\mathrm{O}_{2}$ sensors}

Recently it was shown that the stirring sensitivity of electrochemical $\mathrm{O}_{2}$ sensors can affect EC flux measurements and may cause significant artificial fluxes in the range of actual benthic fluxes (Holtappels et al., 2015). The stirring sensitivity study was conducted under controlled laboratory conditions, which allowed extracting a model to predict the artificial flux for a typical sensor orientation $\left(\mathrm{O}_{2}\right.$ sensor facing the flow) under such controlled conditions. However, it remains difficult to dissect true and artificial fluxes in field measurements because of the variable flow conditions and the similar response of true and artificial fluxes to flow dynamics. Pending availability of sensors with negligible stirring effect, EC data sets have to be carefully evaluated and, if possible, cross-referenced with other methods. The model from Holtappels et al. (2015) can be used to estimate if the potential for artificial fluxes is in the range of the measured fluxes. Applying the model 2 from Holtappels et al. (2015), i.e. using the same sensor characteristics and the measured Reynolds stress of this study, artificial flux estimates ranged from +0.2 to $-8 \mathrm{mmol} \mathrm{m}^{-2} \mathrm{~d}^{-1}$. This range of error estimates indicates that a bias from stirring sensitivity is possible, but there are no means to correct for it. Thus, in our case, we cannot exclude such bias and we also cannot resolve the exact error. However, the two independent reference measurements, chamber incubations and $\mathrm{O}_{2}$ profiles, compare very well with the EC-fluxes, which make us confident that the bias from stirring sensitivity is minor in our case. Furthermore it is important to note that the presented data treatment of the $\mathrm{O}_{2}$ and velocity time series as well as the sensitivity analysis of the crosscorrelation remain applicable and valid irrespective of the true benthic flux. Additional studies are needed to test the applicability of non-stirring sensitive optode sensors to better measure such low $\mathrm{O}_{2}$ fluxes.

\subsection{Benthic oxygen fluxes at HAUSGARTEN}

Benthic oxygen fluxes measured at $2500 \mathrm{~m}$ water depth at HAUSGARTEN by the three techniques (microprofiler, benthic chamber and eddy covariance) are in good agreement. The average $\mathrm{O}_{2}$ flux (DOU) derived from microprofiles is $-1.0 \pm 0.3 \mathrm{mmol}$ $\mathrm{O}_{2} \mathrm{~m}^{-2} \mathrm{~d}^{-1}(\mathrm{SD}, \mathrm{N}=16)$, the TOU obtained from benthic chamber incubations is $-1.1 \pm 0.1 \mathrm{mmol} \mathrm{O}_{2} \mathrm{~m}^{-2} \mathrm{~d}^{-1}(\mathrm{SD}, \mathrm{N}=3)$ and the average EC flux is $-0.9 \pm 0.2 \mathrm{mmol} \mathrm{O} \mathrm{O}_{2} \mathrm{~m}^{-2} \mathrm{~d}^{-1}(\mathrm{SD}, \mathrm{N}=30$ ). Considering that each method measures at a different spatial scale (microprofiled area $625 \mathrm{~cm}^{2}$, benthic chamber incubations area $400 \mathrm{~cm}^{2}$ and EC footprint area - Berg et al. (2007) - 150 $\mathrm{m}^{2}$ ) our data reveal that the benthic oxygen consumption is rather homogenous at this deep sea site. The investigated sediment area at HAUSGARTEN is indeed known to be very homogeneous, with respiration rates comparable to those of abyssal plain food webs that are under strong energy limitation (Soltwedel et al., 2005; 
Van Oevelen et al., 2011).

The shape of the oxygen profiles and the volumetric consumption rates (Fig. 3) suggests that most of the organic matter is aerobically remineralized in the top centimeter without depleting the pore water oxygen. Since the vast majority of organic matter that reaches the seafloor is ultimately mineralized, benthic oxygen fluxes can be used to estimate carbon fluxes (Jahnke, 1996). Assuming a respiratory quotient of 1.0 , our oxygen fluxes can be converted into carbon equivalents resulting in a carbon flux of $4.3 \mathrm{~g} \mathrm{C} \mathrm{m}^{-2} \mathrm{yr}^{-1}$. The annual sedimentation rate of particulate organic matter as measured by sediment traps is estimated as $2.5 \mathrm{~g} \mathrm{C} \mathrm{m}^{-2} \mathrm{yr}^{-1}$ (Bauerfeind et al., 2009). Thus our benthic consumption rates may indicate a deficit in organic matter supply as measured by sediment traps, as it has been observed for other deep sea sites (Smith et al., 2008, Wenzhöfer and Glud, 2002).

Despite some variability (20-30\%) within the 16 microprofiles, the average DOU is not significantly different from the two total flux measurements (one way ANOVA: $F=1.84, p>F=0.17$ ) implying that faunal-mediated $\mathrm{O}_{2}$ transport and consumption are low at this site. This confirms that at HAUSGARTEN central station HG-IV $(2500 \mathrm{~m})$, sediment respiration is dominated by prokaryotes (Van Oevelen et al., 2011), with a small faunal contribution mainly due to the energy limitation. This is the first time that an $\mathrm{O}_{2}$ flux exceeding $-1 \mathrm{mmol} \mathrm{m} \mathrm{m}^{-2} \mathrm{~d}^{-1}$ in deep sea Arctic sediments has been determined and confirmed using three different methodologies at the same site. In situ benthic oxygen flux measurements at Northern high latitudes are still scarce. Diffusive oxygen uptake rates determined mainly from ex situ microprofiles from the HAUSGARTEN area in 2007 and 2008 revealed much lower values, ranging from -0.1 to $-1 \mathrm{mmol} \mathrm{m}^{-2} \mathrm{~d}^{-1}$ (Cathalot et al., 2015). DOU from the same site (HG-IV) showed only half the oxygen consumption (ex situ: $-0.3 \mathrm{mmol} \mathrm{m}^{-2} \mathrm{~d}^{-1}$ (2007) $0.4 \mathrm{mmol} \mathrm{m}^{-2} \mathrm{~d}^{-1}$ (2008), in situ: $-0.2 \mathrm{mmol} \mathrm{m}^{-2} \mathrm{~d}^{-1}$ (2007); Cathalot et al., 2015). Sauter el al. (2001) reported benthic oxygen fluxes from in situ microprofiles in the order of $-0.2 \mathrm{mmol}$ $\mathrm{O}_{2} \mathrm{~m}^{-2} \mathrm{~d}^{-1}$ in the Central Greenland Sea (3600 m depth) and the East Greenland Continental Margin (1950 m depth). These fluxes differ by a factor of 5 to the ones obtained from our measurements, which may be related to differences in primary productivity, degradability of the settling organic matter and interannual variability (Cathalot et al., 2015; Bauerfeind et al., 2009). These findings highlight the need for further investigations in this region, especially as the Arctic Ocean is facing rapid alterations due to climate changes (e.g. Johannessen et al., 2004; Wassmann, 2011; Slagstad et al., 2011). It was shown that the sea ice melting in the summer season produces a stratified euphotic marginal ice zone enriched in nutrients that can cause intense phytoplankton blooms (Bauerfeind et al., 2009), thus regionally enhanced fluxes of particulate organic matter to the seafloor might be possible. Measurements carried out with microprofiles in the Antarctic abyssal plain showed already that, shortly after a phytoplankton bloom, the sediment community oxygen consumption had almost tripled, from -0.4 to $-1.1 \mathrm{mmol} \mathrm{O}_{2} \mathrm{~m}^{-2} \mathrm{~d}^{-1}$ (3000 m depth, Veit-Köhler et al. 2011, see also Witte et al. (2003)).

\section{Final remarks}

A key limitation in understanding the global climate change impact on deep sea benthic communities is the paucity of benthic $\mathrm{O}_{2}$ flux datasets, in particular long-term time series obtained with autonomous instrumentation able to monitor rapid changes in benthic $\mathrm{O}_{2}$ consumption (Smith et al., 2013). To realistically estimate the contribution of the deep ocean seafloor to global carbon remineralization, it is indeed paramount to achieve more and longer time series (Smith et al., 2009, 2013). Long-term investigations over a seasonal cycle capture episodic events such as massive algal deposits (Boetius et al., 2013) that would result in localized hot spots of $\mathrm{O}_{2}$ consumption.

Evidently long-term benthic flux monitoring is potentially better realized with a non-invasive measurement approach, although the microscale features would be missed. In principle, the measurement of mean $\mathrm{O}_{2}$ concentration gradients in the benthic boundary layer (Holtappels et al., 2011a) in combination with the determination of the turbulent diffusion (Holtappels and Lorke, 2011b) allows estimating the $\mathrm{O}_{2}$ uptake. However, low benthic $\mathrm{O}_{2}$ uptakes as the ones measured in this study, result in small $\mathrm{O}_{2}$ concentration gradients $<5 \times 10^{-5} \mathrm{mmol} \mathrm{m}^{-1}$, which must be resolved during a long-term measurement. This requires the use of extremely stable high precision $\mathrm{O}_{2}$ sensors that do not yet exist. Conveniently this requirement is excluded for EC measurements because the temporal drift is not relevant (to a reasonable extent) as turbulent fluxes are computed only from the fluctuations around the mean. However, given the complex evaluation of the EC fluxes when approaching the method's detection limit, and in order to include small scale benthic biogeochemical processes, the use of profiling systems and chambers coupled to non-invasive techniques seems to be the best strategy.

\section{Acknowledgments}

The authors are thankful to the RV Polarstern captain and ship crew, ARK XXIV/2 chief scientist Thomas Soltwedel, the lander technicians A. Nordhausen, V. Asendorf, P. Meyer, the microsensor technicians form Max Planck Institute for Marine Microbiology, and Ronnie Glud for his helpful contribution to an early stage discussion. This work was financially supported by the Max Planck Society, EU 7th FP "SENSEnet" (PITN-GA-2009-237868), the Helmholtz Alliance "ROBEX", the Helmholtz Society, and the DFGResearch Center/Cluster of Excellence "The Ocean in the Earth System" at the University of Bremen (http://www.marum.de). This is publication "e39084" of the Alfred-Wegener-Institut HelmholtzZentrum für Polar- und Meeresforschung, Bremerhaven, Germany.

\section{References}

Bauerfeind, E., Nothig, E.M., Beszczynska, A., Fahl, K., Kaleschke, L., Kreker, K., Klages, M., Soltwedel, T., Lorenzen, C., Wegner, J., 2009. Particle sedimentation patterns in the eastern Fram strait during 2000-2005: results from the Arctic long-term observatory HAUSGARTEN. Deep Sea Res. I 56, 1471-1487.

Berg, P., Risgaard-Petersen, N., Rysgaard, S., 1998. Interpretation of measured concentration profiles in sediment pore water. Limnol. Oceanogr. 43, 1500-1510.

Berg, P., Roy, H., Janssen, F., Meyer, V., Jorgensen, B.B., Huettel, M., de Beer, D., 2003 Oxygen uptake by aquatic sediments measured with a novel non-invasive eddy correlation technique. Mar. Ecol. Prog. Ser. 261, 75-83.

Berg, P., Roy, H., Wiberg, P.L., 2007. Eddy correlation flux measurements: the sediment surface area that contributes to the flux. Limnol. Oceanogr. 52, $1672-1684$

Berg, P., Glud, R.N., Hume, A., Stahl, H., Oguri, K., Meyer, V., Kitazato, H., 2009. Eddy correlation measurements of oxygen uptake in deep ocean sediments. Limnol. Oceanogr. Methods 7, 576-584.

Berg, P. Long, M.H., Huettel, M., Rheuban, J.E., McGlathery, J.K., Howarth, R.W. Foreman, K.H., Giblin, A.E., Marino, R., 2013. Eddy correlation measurements of oxygen fluxes in permeable sediments exposed to varying current flow and light, Limnol. Oceanogr. Methods 58 (4), 1329-1343.

Boetius, A., Albrecht, S., Bakker, K., Bienhold, C., Felden, J., Fernández-Méndez, M., Party, R.V., 2013. Export of Algal biomass from the melting Arctic sea ice. Science 339 (6126), 1430-1432. http://dx.doi.org/10.1126/science.1231346.

Brand, A., Mcginnis, D.F., Wehrli, B., Wu, A., 2008. Intermittent oxygen flux from the interior into the bottom boundary of lakes as observed by eddy correlation. Limnol. Oceanogr. 53 (5), 1997-2006.

Cabrera, R., Deines, K., Brumley, B., Terray, E., 1987. Development of a practical coherent acoustic Doppler current profiler. In: Proceedings of Oceans '87, Halifax, NS, Canada, IEEE Oceanic Engineering Society, pp. 93-97.

Cathalot, C., Rabouille, C., Sauter, E., Schewe, I., Soltwedel, T., 2015. Benthic oxygen uptake in the Arctic ocean margins - a case study at the Deep-Sea observatory HAUSGARTEN (Fram strait). PLoS ONE 10 (10), e0138339. http://dx.doi.org/ 
10.1371/journal.pone.0138339.

Chipman, L., Huettel, M., Berg, P., Meyer, V., Klimant, I., Glud, R., Wenzhoefer, F. 2012. Oxygen optodes as fast sensors for eddy correlation measurements in aquatic systems. Limnol. Oceanogr.: Methods 10, 304-316. http://dx.doi.org/ 10.4319/lom.2012.10.304

Donis, D., Holtappels, M., Noss, C., Cathalot, C., Hancke, K., Polsenaere, P., Lorke, A., Glud, R.N., Wenzhöfer, F., Meysman, F.J.R., McGinnis, D.F., 2015. An assessment of the precision and confidence of aquatic eddy correlation measurements. J. Atmos. Ocean. Technol. 32, 642-655. http://dx.doi.org/10.1175/ JTECH-D-14-00089.1.

Elgar, S., Raubenheimer, B., Guza, R.T., 2005. Quality control of acoustic Doppler velocimeter data in the surfzone 2005. Meas. Sci. Technol. 16 (2005), 1889-1893. http://dx.doi.org/10.1088/0957-0233/16/10/002.

Fahrbach, E., Meincke, J., Osterhus, S., Rohardt, G., Schauer, U., Tverberg, V., Verduin, J., 2001. Direct measurements of volume transports through Fram strait. Polar Res. 20 (2), 217-224.

Forest, A., Wassmann, P., Slagstad, D., Bauerfeind, E., Nothig, E.M., Klages, M., 2010 Relationships between primary production and vertical particle export at the Atlantic-Arctic boundary (Fram strait, HAUSGARTEN). Polar Biol. . http://dx.doi org/10.1007/s00300-010-0855-3S

Gage, J.D., Tyler, P.A., 1991. Deep-Sea Biology: A Natural History of Organisms at the Deep-Sea Floor. Cambridge University Press, Cambridge, UK.

Glud, R.N., Gundersen, J.K., Jørgensen, B.B., Revsbech, N.P., Schulz, H.D., 1994. Diffusive and total oxygen-uptake of deep-sea sediments in the eastern southatlantic ocean - in-situ and laboratory measurements. Deep-Sea Res. I 41 $1767-1788$.

Glud, R.N., Gundersen, J.K., Røy, H., Jørgensen, B.B., 2003. Seasonal dynamics of benthic $\mathrm{O} 2$ uptake in a semi-enclosed bay: importance of diffusion and fauna activity. Limnol. Oceanogr. 48, 1265-1276.

Glud, R.N., Wenzhöfer, F., Tengberg, A., Middelboe, M., Oguri, K. Kitasato, H., 2005. Distribution of oxygen in surface sediments from Central Sagami bay, Japan: in situ measurements by microelectrodes and planar optodes. Deep-Sea Res. 52, 1974-1987.

Glud, R., 2008. Oxygen dynamics of marine sediments. Mar. Biol. Res. 4, 243-289.

Glud, R.N., Berg, P., Hume, A., Batty, P., Blicher, M.E., Lennert, K., Rysgaard, S., 2010 Benthic oxygen exchange across hard- bottom substrates quantified by eddy correlation in a sub-Arctic fjord. Mar. Ecol. Prog. Ser. 417, 1-12.

Gooday, A.J., Turley, C.M., 1990. Responses by benthic organ- isms to inputs of organic material to the ocean floor: a review. Philos. Trans. R. Soc. Lond. Ser. A 331, 119-138.

Goring, D.G., Nikora, V.I., 2002. Despiking acoustic Doppler velocimeter data. J. Hydraul. Eng. 128, 117-126.

Graf, G., 1989. Bentho-pelagic coupling in a deep-sea benthic community. Nature 341, 437-439.

Grasshoff, K., Ehrhardt, M., Kremling, K., 1983. Methods of Sea Water Analysis. Verlag Chem., Weinheim.

Grenz, C., Denis, L., Boucher, G., Chauvaud, L., Clavier, J., Fichez, R., Pringault, O., 2003. Spatial variability in sediment oxygen consumption under winter conditions in a lagoonal system in New Caledonia (South Pacific). J. Exp. Mar. Biol. Ecol. 2853347.

Gundersen, J.K., Jørgensen, B.B., 1990. Microstructure of diffusive boundary layers and the oxygen uptake of the sea floor. Nature 345604 7.

Gundersen, J.K., Ramsing, N.B., Glud, R.N., 1998. Predicting the signal of $02 \mathrm{mi}-$ crosensors from physical dimensions, temperature, salinity, and 02 concentration. Limnol. Oceanogr. 43, 1932-1937.

Holtappels, M., Kuypers, M.M., Schlüter, M., Brüchert, V., 2011a. Measurement and interpretation of solute concentration gradients in the benthic boundary layer. Limnol. Oceanogr.: Methods 9, 1-13.

Holtappels, M., Lorke, A., 2011b. Estimating turbulent diffusion in a benthic boundary layer. Limnol. Oceanogr.: Methods 9, 29-41.

Holtappels, M., Glud, R.N., Donis, D., Liu, B., Hume, A., Wenzhöfer, F., Kuypers, M.M. M., 2013. Effects of transient bottom water currents and oxygen concentrations on benthic exchange rates as assessed by eddy correlation measurements. J Geophys. Res.: Oceans 118 (3), 1157-1169.

Holtappels, M., Noss, C., Hancke, K., Cathalot, C., McGinnis, D.F., Lorke, A., et al., 2015. Aquatic eddy correlation: quantifying the artificial flux caused by stirring sensitive $\mathrm{O}_{2}$ sensors. PLoS ONE 10 (1), e0116564. http://dx.doi.org/10.1371/ journal.pone.0116564.

Hume, A.C., Berg, P., McGlathery, K.J., 2011. Dissolved oxygen fluxes and ecosystem metabolism in An eelgrass (Zostera marina) meadow measured with the eddy correlation technique. Limnol. Oceanogr. 56, 86-96.

Johannessen, O.M., Bengtsson, L., Miles, M.W., Kuzmina, S.I., Semenov, V.A., Alekseev, G.V., Nagurnyi, A.P., Zakharov, V.F., Bobylev, L.P., Pettersson, L.H., Hasselmann, K., Cattle, A.P., 2004. Arctic climate change: observed and modelled temperature and sea-ice variability. Tellus Ser.

Jahnke, R.A., Christiansen, M.B., 1989. A free-vehicle benthic chamber instrument for seaf loor studies. Deep Sea Res. Part A 36, 625-637.

Jahnke, R.A., 1996. The global ocean flux of particulate organic carbon: areal distribution and magnitude. Glob. Biogeochem. Cycles 107188.

Jørgensen, B.B., Revsbech, N.P., 1985. Diffusive boundary layers and the oxygen uptake of sediment and detritus. Limnol. Oceanogr. 30, 111-122.

Kuwae, T., Kamio, K., Inoue, T., Miyoshi, E., Uchiyama, Y., 2006. Oxygen exchange flux between sediment and water in An intertidal sand flat, measured in-situ by the eddy-correlation method. Mar. Ecol. Prog. Ser. 307, 59-68.

Lee, X., Massman, W., Law, B., 2004. Handbook of Micrometeorology: A Guide for Surface Flux Measurement and Analysis. Kluwer Academic Publishers.
Lhermitte, R., Lemmin, U., 1994. Open-channel flow and turbulence measurement by high-resolution Doppler sonar. J. Atmos. Ocean. Technol. 11, 1295-1308.

Li, Y.H., Gregory, S., 1974. Diffusion of ions in SEA water and in deep-sea sediments. Geochim. Cosmochim. Acta 38, 703-714.

Long, M.H., Berg, P., de Beer, D., Zieman, J.C., 2013. In Situ coral reef oxygen metabolism: an eddy correlation study. PLoS ONE 8 (3), e58581.

Lorke, A., Mu, B., Maerki, M., Wu, A., 2003. Breathing sediments: the control of diffusive transport across the sediment - water interface by periodic boundarylayer turbulence. LImnol. Oceanogr. 48 (6), 2077-2085.

Lorrai, C., McGinnis, D.F., Berg, P., Brand, A., Wüest, A., 2010. Application of oxygen eddy correlation in aquatic systems. J. Atmos. Ocean. Technol. 27, 1533-1546.

Manley, O., 1995. Branching of Atlantic water within the Greenland-Spitsbergen passage: an estimate of recirculation. J. Geophys. Res. 100 (C10), 20627-20634.

McGinnis, D.F., Berg, P., Brand, A., Lorrai, C., Edmonds, T., Wüest, A., 2008. Measurements of eddy correlation oxygen fluxes in shallow freshwaters: towards routine applications and analysis. Geophys. Res. Lett. 35, 1-5.

McGinnis, D.F., Cherednichenko, S., Sommer, S., Berg, P., Rovelli, L., Schwarz, R. Linke, P., 2011. Simple, robust eddy correlation amplifier for aquatic dissolved oxygen and Hydrogen sulfide flux measurements. Limnol. Oceanogr.: Methods 9, 340-347.

McGinnis, D.F., Sommer, S., Lorke, A., Glud, R.N., Linke, P., 2014. Quantifying tidally driven benthic oxygen exchange across permeable sediments: an aquatic eddy correlation study. J. Geophys. Res.: Oceans 119 (10), 6918-6932.

Pfannkuche, O., 1993. Benthic response to the sedimentation of particulate organic matter at the BIOTRANS station, 471N, 201W. Deep-Sea Res. II 40, 135-149.

Rabouille, C., Denis, L., Dedieu, K., Stora, G., Lansard, B., Grenz, C., 2003. Oxygen demand in coastal marine sediments: comparing in situ microelectrodes and laboratory CORE incubation. J. Exp. Mar. Biol. Ecol. 2854969.

Rasmussen, H., Jsrgensen, B.B., 1992. Microelectrode studies of seasonal oxygen uptake in a coastal sediment: role of molecular diffusion, 81, 289-303. (Hulth S., Blackburn, T.H., hall, P.O.J., 1994. Arctic sediments (Svalbard)-consumption and microdistribution of oxygen. Mar. Chem. 46, 293-316.

Reimers, C.E., Fischer, K.M., Merewether, R., Smith Jr., K.L., Jahnke, R.A., 1986. Oxygen microprofiles measured in situ in deep ocean sediments. Nature 320 $741-744$.

Reimers, C.E., 1987. An in situ microprofiling instrument for measuring interfacial pore water. gradients: methods and oxygen profiles from the North Pacific Ocean. Deep-Sea Res. I 34, 2019-2035.

Reimers, C.E., Tuba Ozkan-Haller, H., Berg, P., Devol, A., McCann-Grosvenor, K. Sanders, R.D., 2012. Benthic oxygen consumption rates during hypoxic conditions on the Oregon continental shelf: evaluation of the eddy correlation method. J. Geophys. Res. 117, 1-18.

Revsbech, N.P., 1989. An oxygen microsensor with a guard cathode. Limnol. Oceanogr. 34, 474-478.

Rheuban, J.E., Berg, P., 2013. The effects of spatial and temporal variability at the sediment surface on aquatic eddy correlation flux measurements. Limnol. Oceanogr.: Methods 11, 351-359. http://dx.doi.org/10.4319/lom.2013.11.351.

Sachs, O., Sauter, E.J., Schlüter, M., Rutgers van der Loeff, M.M., Jerosch, K., Holby, O., 2009. Benthic organic carbon flux and oxygen penetration reflect different plankton provinces in the southern ocean. Deep-Sea Res. Part I: Ocean. Res. Pap. 56, 1319-1335. http://dx.doi.org/10.1016/j.dsr.2009.02.003.

Sauter, E.J., Schlüter, M., Suess, E., 2001. Organic carbon flux and remineralization in surface sediments from the northern North Atlantic derived from pore-water oxygen microprofiles. Deep-Sea Res. I 48 (2), 529-553.

Schauer, U., Beszczynska-Moeller, A., Walczowski, W., Fahrbach, E., Piechura, J., Hansen, E., 2008. Variation of measured heat flothrough the Fram Strait between 1997 and 2006. In: Dickson, R.R., Meincke, J., Rhines, P. (Eds.), ArcticSubarctic Ocean Fluxes. Springer, Netherlands, pp. 65-85.

Schlitzer, R., 2005. Ocean data view. 〈http:www.awi-bremerhaven.de/GEO/ODV .

Slagstad, D., Ellingsen, I.H., Wassmann, P., 2011. Evaluating primary and secondary production in An Arctic ocean void of summer sea ice: an experimental simulation approach. Prog. Oceanogr. 90, 117-131.

Smith, K.L., 1978. Bentic community respiration in the N.W. Atlantic ocean: in situ measurements from 40 to $5200 \mathrm{~m}$. Mar. Biol. 47, 337-347.

Smith, K.L., Hinga, K.R., 1983. Sediment community respiration in the deep sea. In: Rowe, G.T. (Ed.), The Sea 8. Wiley, New York, pp. 331-370.

Smith, K.L., Ruhl, H.A., Kaufmann, R.S., Diego, S., 2008. Tracing abyssal food supply back to upper-ocean processes over a 17-year time series in the northeast Pacific. Limnol. Oceanogr. 53 (6), 2655-2667.

Smith, K.L., Ruhl, H. A, Bett, B.J., Billett, D.S.M., Lampitt, R.S., Kaufmann, R.S., 2009. Climate, carbon cycling, and deep-ocean ecosystems. Proc. Natl. Acad. Sci. USA 106 (46), 19211-19218. http://dx.doi.org/10.1073/pnas.0908322106.

Smith, K.L., Ruhl, H. A, Kahru, M., Huffard, C.L., Sherman, A.D., 2013. Deep ocean communities impacted by changing climate over $24 \mathrm{y}$ in the abyssal northeast pacific ocean. Proc. Natl. Acad. Sci. USA 110 (49), 19838-19841.

Soltwedel, T., Bauerfeind, E., Bergmann, M., Budaeva, N., Hoste, E., Jaeckisch, N., Juterzenka, K. v, Matthießen, J., Mokievsky, V., Nöthig, E.M., Quéric, N., Sablotny, B., Sauter, E., Schewe, I., Urban-Malinga, B., Wegner, J., Wlodarska-Kowalczuk, M., Klages, M., 2005. HAUSGARTEN: multidisciplinary investigations at a deepsea, long-term observatory in the Arctic ocean. Oceanography 18 (3), 46-61.

SonTek, 2004. SonTek ADVField Acoustic Doppler Velocimeter: Technical Documentation. SonTek/YSI, SanDiego,CA, p. 186.

Tengberg, A., de Bovee, Hall, P., Berelson, W., Chadwick, D., Ciceri, G., Crassous, P., Devol, A., Emerson, S., Gage, J., Glud, R., Graziottini, F., Gundersen, J., Hammond, D., Helder, W., Hinga, K., Holby, O., Jahnke, R., Khripounoff, A., Liebermann, S. Nuppenau, V., Pfannkuche, O., Reimers, C., Rowe, G., Sahami, A., Sayles, F., 
Schurter, A., Smallman, D., Wehrli, B., de Wilde, P., 1995. Benthic chamber and profiling landers in oceanography-a review of design, technical solutions and functioning. Prog. Oceanogr. 35, 253-294.

Van Oevelen, D., Bergmann, M., Soetaert, K., Bauerfeind, E., Hasemann, C., Klages, M., Schewe, I., Soltwedel, T., Budaeva, N.E., 2011. Carbon flows in the benthic food web at the deep-sea observatory HAUSGARTEN (Fram strait). Deep-Sea Res. I 58, 1069-1083.

Veit-Köhler, G., Guilini, K., Peeken, I., Sachs, O., Sauter, E.J., Würzberg, L., 2011. Antarctic deep-sea meiofauna and bacteria react to the deposition of particulate organic matter after a phytoplankton bloom. Deep Sea Res. Part II: Top. Stud. Oceanogr. 58 (19-20), 1983-1995.

Vinje, T.E., 1977. Sea ice conditions in the European sector of the marginal seas of the Arctic, 1966-75. Nor. Polarinst. Arbok 1975, 163-174.
Vinje, T.E., 1985. Sea ice distribution 1971-80. Norsk Polarinstitutt Skifter 179D. Wassmann, P., 2011. Arctic marine ecosystems in an era of rapid climate change. Prog. Oceanogr. 90 (1-4), 1-17.

Wenzhöfer, F., Glud, R.N., 2002. Benthic carbon mineralization in the Atlantic: a synthesis based on in situ data from last decade. Deep-Sea Res. I 4912551279

Witte, U., Pfannkuche, O., 2000. High rates of benthic carbon remineralisation in the abyssal Arabian sea. Deep Sea Res. Part II 47, 2785-2804.

Witte, U., Aberle, N., Sand, M., Wenzhöfer, F., 2003. Rapid response of a deep-sea benthic community to POM enrichment: an in situ experimental study. Mar. Ecol. Prog. Ser. 251, 27-36.

Zedel, L., Hay, E., Lohrmann, A., 1996. Performance of single beam pulse-to-pulse coherent Doppler profiler. IEEE J. Ocean. Eng. 21, 290-299. 